\title{
Fluoroscopic and Endoscopic Gastrostomy Tube Placement: Regional Variation and Their Prevalence
}

\author{
Syed I. Khalid ${ }^{1} \quad$ Rita Wu$^{2} \quad$ Ayoolamide Gazal ${ }^{3} \quad$ Jordan C. Tasse ${ }^{1} \quad$ David M. Tabriz $^{1} \quad$ Sreekumar Madassery ${ }^{1}$ \\ Ulku C. Turba' Bulent Arslan
}

${ }^{1}$ Division of Vascular and Interventional Radiology, Rush University Medical Center, Chicago, Illinois, United States

${ }^{2}$ Chicago Medical School, North Chicago, Illinois, United States

${ }^{3}$ Rush University School of Medicine, Chicago, Illinois, United States

Address for correspondence Syed I. Khalid, MD, Division of Interventional Radiology, Rush University Medical Center, Professional Building, 1725 W. Harrison St., Suite 450, Chicago, IL 60612, United States (e-mail: syed.khalid@me.com).

\begin{abstract}
Keywords

- gastrostomy

- G-tube

- percutaneous endoscopic gastrostomy

- endoscopic

- fluoroscopic
\end{abstract}

Objective This study aims to assess the regional variation and overall longitudinal prevalence of approaches to gastrostomy tube placement in patients covered by Medicare or Medicaid.

Background Gastrostomy tubes are most commonly inserted endoscopically given the approaches' demonstrated safety, success, and patient outcomes as compared with laparoscopic approaches. Recently, the growth of interventional radiology services has provided patients with an alternative percutaneous approach. The safety and efficacy of this approach as opposed to endoscopic approaches has yet to be determined.

Methods From 2005 to 2014, Medicare Standard Analytic Files derived from Medicare parts $A$ and $B$, which contain $100 \%$ of inpatient and outpatient facility records billed to Medicare, were retrospectively analyzed. Age, sex, year of placement, region, comparative quarterly ratio, regional cost variation, and overall financial cost were compared between both cohorts.

Results Our population included a total of 336,021 patients; of those, 30,327 patients underwent fluoroscopic guided procedures, and 305,694 patients underwent endoscopic procedures. Age $(p<0.001)$, region $(p=0.043)$, and year of placement $(p<0.001)$ varied significantly between these populations. Fluoroscopic-guided procedures were found to have a statistically significantly lower average cost of treatment compared with endoscopic gastrostomies $(\$ 2,018.62$ vs. $\$ 2,471.33$, respectively, $p=0.03$ ).

Conclusion This study demonstrates an increasing prevalence of fluoroscopically placed gastrostomy tubes as compared with those placed endoscopically.

\section{Introduction}

Gastrostomy tubes are commonly used to provide nutrition, hydration, and medication to patients with oral intake difficulties or patients with complex medical conditions who have functional gastrointestinal systems. ${ }^{1}$ Although gastrostomy tubes have traditionally been placed using open surgical technique, since their introduction in the 1980s minimally invasive techniques including percutaneous endoscopic insertion and fluoroscopic guidance insertion have become adequate alternatives. ${ }^{2-5}$ Early studies of these
DOI https://doi.org/

10.1055/s-0039-1685240 ISSN 2457-0214. minimally invasive techniques have reported high rates of success (99.2\% for fluoroscopic, $95.7 \%$ for endoscopic) with significantly less major complications compared with open surgery (5.9\% for fluoroscopic vs. $9.4 \%$ for endoscopic and $19.9 \%$ for open surgery). ${ }^{6}$ Common complications noted in the literature include wound infections, hemorrhage, gastroesophageal reflux, aspiration pneumonia, and/or mechanical failure. ${ }^{7-10}$ Much of the existing literature on comparisons of endoscopic versus fluoroscopic gastrostomies is from outside of the United States or limited to single-institution or single-region analysis. ${ }^{11}$ This study aims to summarize the cost
License terms

Vascular and Interventional Radiology

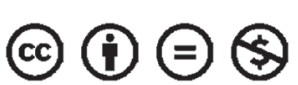


Table 1 Descriptive characteristics of patients undergoing gastrostomy procedures

\begin{tabular}{|c|c|c|c|c|c|c|c|}
\hline \multirow{2}{*}{$\begin{array}{l}\text { Parameters } \\
\text { Age, } n(\%)\end{array}$} & \multicolumn{2}{|c|}{ Total $(n=336,021)$} & \multicolumn{2}{|c|}{ Fluoroscopic $(n=30,327)$} & \multicolumn{2}{|c|}{ Endoscopic $(n=305,694)$} & \multirow{2}{*}{$\begin{array}{l}p \text { Value } \\
<0.001\end{array}$} \\
\hline & & & & & & & \\
\hline$<64$ & 60,045 & $(17.9)$ & 6,224 & $(20.5)$ & 53,821 & $(17.6)$ & \\
\hline $65-69$ & 42,704 & $(12.7)$ & 5,142 & $(17.0)$ & 37,562 & $(12.3)$ & \\
\hline $70-74$ & 45,197 & (13.5) & 4,782 & $(15.8)$ & 40,415 & $(13.2)$ & \\
\hline $75-79$ & 50,839 & $(15.1)$ & 4,345 & $(14.3)$ & 46,494 & $(15.2)$ & \\
\hline $80-84$ & 54,666 & $(16.3)$ & 4,278 & $(14.1)$ & 50,388 & $(16.5)$ & \\
\hline$>85$ & 79,275 & $(23.6)$ & 5,282 & $(17.4)$ & 73,993 & $(24.2)$ & \\
\hline Unknown & 3,295 & $(1.0)$ & 274 & $(0.9)$ & 3,021 & $(1.0)$ & \\
\hline Sex, $n(\%)$ & & & & & & & 0.14 \\
\hline Male & 158,401 & $(47.1)$ & 16,272 & $(53.7)$ & 142,129 & $(46.5)$ & \\
\hline Female & 174,324 & (51.9) & 13,780 & $(45.4)$ & 160,544 & $(52.5)$ & \\
\hline Unknown & 3,296 & $(1.0)$ & 275 & $(0.9)$ & 3,021 & $(1.0)$ & \\
\hline Region, $n(\%)$ & & & & & & & $0.043^{*}$ \\
\hline Northeast & 52,628 & $(15.7)$ & 5,014 & $(16.5)$ & 47,614 & $(15.6)$ & \\
\hline Midwest & 74,115 & $(22.1)$ & 6,042 & $(19.9)$ & 68,073 & $(22.3)$ & \\
\hline South & 152,972 & $(45.5)$ & 12,146 & $(40.1)$ & 140,826 & $(46.1)$ & \\
\hline West & 56,227 & (16.7) & 7,124 & $(23.5)$ & 49,103 & $(16.1)$ & \\
\hline Unknown & 78 & $(0.0)$ & 0 & $(0.0)$ & 78 & $(0.0)$ & \\
\hline Year, n (\%) & & & & & & & $<0.001^{*}$ \\
\hline 2005 & 3,021 & (0.9) & 0 & $(0.0)$ & 3,021 & $(1.0)$ & \\
\hline 2006 & 31,756 & (9.5) & 0 & $(0.0)$ & 31,756 & $(10.4)$ & \\
\hline 2007 & 31,331 & (9.3) & 0 & $(0.0)$ & 31,331 & $(10.2)$ & \\
\hline 2008 & 34,751 & $(10.3)$ & 3,842 & $(12.7)$ & 30,909 & $(10.1)$ & \\
\hline 2009 & 35,779 & $(10.6)$ & 3,976 & $(13.1)$ & 31,803 & $(10.4)$ & \\
\hline 2010 & 35,227 & $(10.5)$ & 4,084 & $(13.5)$ & 31,143 & $(10.2)$ & \\
\hline 2011 & 35,701 & $(10.6)$ & 4,187 & $(13.8)$ & 31,514 & $(10.3)$ & \\
\hline 2012 & 35,461 & $(10.6)$ & 4,701 & $(15.5)$ & 30,760 & $(10.1)$ & \\
\hline 2013 & 34,456 & $(10.3)$ & 4,660 & $(15.4)$ & 29,796 & (9.7) & \\
\hline 2014 & 34,115 & $(10.2)$ & 4,877 & $(16.1)$ & 29,238 & (9.6) & \\
\hline $\begin{array}{l}\text { Average billed/ } \\
\text { patient }(\$)\end{array}$ & $2,244.98$ & & $2,018.62$ & & $2,471.33$ & & $0.03^{*}$ \\
\hline
\end{tabular}

*Significant variables $(p<0.05)$.

and regional trends between endoscopic versus fluoroscopic gastrostomies nationally in patients covered by Medicare in the United States.

\section{Patients and Methods}

Medicare Standard Analytic Files derived from Medicare parts $A$ and $B$, which contain $100 \%$ of inpatient and outpatient facility records billed to Medicare from 2005 to 2014, were retrospectively analyzed. Patients undergoing gastrostomy tube placement were identified based on Current Procedural Terminology (CPT) codes. Total 336,021 patients were identified; of those, 30,327 patients underwent gastrostomy tube insertion under fluoroscopic guidance (defined by CPT49440), and 305,694 patients underwent gastrostomy tube insertion under endoscopic guidance (CPT-43246).

Patients were stratified by age, sex, year of placement, region, and cost. Comparative quarterly ratio and regional cost variations within the United States were compared between both cohorts. Cost was defined as total billed by a given provider for the procedure performed. Statistical analysis was performed using R-Studio (Version 1.0.136). Student's $t$-test was used for categorical variables, with significance level of $p<0.05$. 


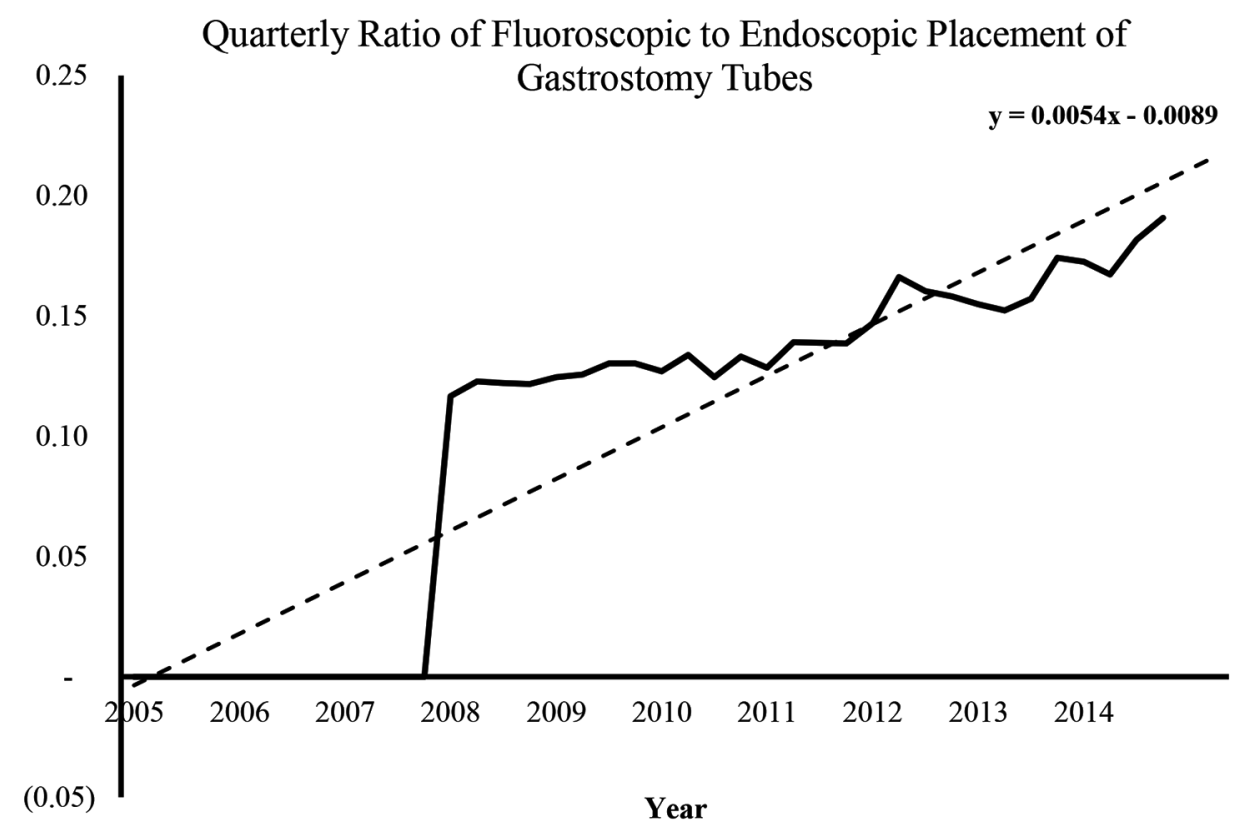

Fig. 1 Quarterly ratio of fluoroscopic to endoscopic placement of gastrostomy tubes.

Table 2 Average charges associated with gastrostomy procedures by region

\begin{tabular}{|l|l|l|}
\hline & \multicolumn{2}{|l|}{ Average charge/patient (\$) \pm SD } \\
\hline Region & $\begin{array}{l}\text { Fluoroscopic } \\
\text { gastrostomy }\end{array}$ & $\begin{array}{l}\text { Endoscopic } \\
\text { gastrostomy }\end{array}$ \\
\hline Midwest & $1,932.61 \pm 1,500.89$ & $2,190.54 \pm 1,285.74$ \\
\hline $\begin{array}{l}\text { North- } \\
\text { east }\end{array}$ & $2,042.19 \pm 1,347.89$ & $2,389.05 \pm 1,782.84$ \\
\hline South & $1,747.06 \pm 1,427.05$ & $2,425.80 \pm 1,635.40$ \\
\hline West & $2,525.01 \pm 2,229.45$ & $3,082.10 \pm 1,998.37$ \\
\hline Unknown & - & $1,166.62 \pm 565.24$ \\
\hline
\end{tabular}

Abbreviation: SD, standard deviation.

\section{Results}

From 2005 to 2014, 336,021 patients underwent gastrostomy tube placement, with 30,327 under fluoroscopic guidance and 305,694 under endoscopic guidance. Age breakdown differed significantly between the fluoroscopic and endoscopic cohorts (-Table 1). There was a significantly higher prevalence of fluoroscopic procedures in patients age < 64 (20.5 vs. 17.6\%), 65 to 69 (17.0 vs. $12.3 \%$ ), and 70 to 74 years (15.8 vs. $13.2 \%$ ). Conversely, there was a higher prevalence of endoscopic procedures in patients age 75 to 79 (14.3 vs. $15.2 \%$ ), 80 to 84 (14.1 vs. $16.5 \%$ ), and > 85 (17.4 vs. $24.2 \%$ ). Males accounted for $53.7 \%$ ( $n=16,272$ ) of patients undergoing the fluoroscopic approach and $46 \%$ ( $n=142,129)$ of patients undergoing the endoscopic approach. Regional variations were significant among both cohorts with $40.1 \%$ of fluoroscopic gastrostomy placements occurring in the south, $23.5 \%$ in the west, $19.9 \%$ in the midwest, and $16.5 \%$ in the northeast compared with $46.1 \%$ in the south, $22.3 \%$ in the mid-west, $16.1 \%$ in the west, and $15.6 \%$ in the northeast for endoscopic gastrostomy procedures ( $p=0.043$ ). The quarterly ratio of fluoroscopic to endoscopic gastrostomies gradually increased between 2008 and 2014 (-Fig. 1).

Fluoroscopic-guided gastrostomies were found to have a significantly lower average cost of treatment compared with endoscopic gastrostomies (\$2018.62 vs. \$2,471.33 respectively, $p=0.03$ ). This was true for every region of the United States (-Table 2).

\section{Discussion}

Our analysis of the 336,021 gastrostomy procedures from 2005 to 2014 indicates the growing prevalence of fluoroscopic guidance in gastrostomy placements compared with the traditional endoscopic approach. Fluoroscopic gastrostomy compared with endoscopic gastrostomy had a higher prevalence in southern and mid-western regions (45.5 vs. 40.1\%, 22.1 vs. 19.9\%, respectively). Previous literature has suggested the safety and efficacy of fluoroscopic gastrostomies with comparable complication and failures rates to endoscopic surgery. ${ }^{7,9,10,12-17}$ An early randomized control trial by Hoffer et al evaluating 135 gastrostomy patients (66 fluoroscopic, 69 endoscopic) showed higher success rates and fewer incidences of postoperative complications (mainly in incidence of pneumonia) in the fluoroscopic cohort. ${ }^{7}$ A more recent, retrospective, single-institution study by Allen et al evaluating the two gastrostomy approaches in patients with amyotrophic lateral sclerosis (ALS) showed significantly lower incidences of tube failure and postoperative aspiration in the fluoroscopic group compared with endoscopic group (1.9 vs. $15.7 \%$ failure; 0 vs. $10.5 \%$ postoperative aspiration $).{ }^{17}$

Our evaluation of cost differences between fluoroscopic and endoscopic gastrostomies showed significantly lower 
average cost for patients undergoing fluoroscopic procedures ( $\$ 2018.62$ vs. $\$ 2,471.33$, respectively, $p=0.03$ ). An early study by Barkmeier et al of 121 gastrostomy patients found costs of successful fluoroscopic gastrostomy averaging $\$ 1,985 \pm \$ 418$ compared with $\$ 1,862 \pm \$ 670$ for percutaneous endoscopic tube placement. ${ }^{18}$ Average cost was calculated as a sum of preprocedural, procedural, and postprocedural costs that included costs associated with imaging, intravenous sedation, and costs associated with follow-up management of the tubes. The higher cost associated with fluoroscopic gastrostomy was suggested to be due to the cost of imaging to document the tube position associated with the procedural cost. There was a $100 \%$ success rate for first-time tube placement for fluoroscopically placed tubes but only an $84 \%$ success rate for endoscopically placed tubes. All failed tubes subsequently underwent successful fluoroscopic placement. Cost of replacement was not included in their analysis. Furthermore, cost analysis by Hoffer et al also showed a 2.3 times higher average procedural cost for fluoroscopic surgery compared with endoscopic surgery (with average $57 \%$ greater Medicare reimbursement), which reflects the absence of room charge and shorter staff time requirements associated with endoscopic surgery. ${ }^{7}$ Higher cost associated with fluoroscopic surgery was also attributed to a higher premium charge for fluoroscopic guidance. Interestingly, this cost difference was noted to be offset by cost of complications (endoscopic surgery was found to have higher complication costs associated largely due to additional length of stay). The comparable cost and safety of fluoroscopically guided gastrostomies suggest indications for the growing prevalence of these procedures in the interventional radiology suite.

\section{Limitations}

Administrative data allow for access to a large number of medical data files with long-term tracking of certain identifiers within the coding system. However, these data are usually meant for financial and administrative purposes rather than for research. The accuracy and detail of this data may be less reliable as it necessitates using diagnostic coding that relies on subjective interpretation of physician records by a medical reviewer.

\section{Conclusion}

This study demonstrates an increasing prevalence of fluoroscopically guided gastrostomies as compare endoscopic gastrostomies, with a greater prevalence of fluoroscopic procedures in the south and mid-western regions.

\section{Conflict of Interest}

None.

\section{References}

1 Soscia J, Friedman JN. A guide to the management of common gastrostomy and gastrojejunostomy tube problems. Paediatr Child Health 2011;16(5):281-287
2 Preshaw RM. A percutaneous method for inserting a feeding gastrostomy tube. Surg Gynecol Obstet 1981;152(5):658-660

3 Gibson SE, Wenig BL, Watkins JL. Complications of percutaneous endoscopic gastrostomy in head and neck cancer patients. Ann Otol Rhinol Laryngol 1992;101(1):46-50

4 Larson DE, Burton DD, Schroeder KW, DiMagno EP. Percutaneous endoscopic gastrostomy. Indications, success, complications, and mortality in 314 consecutive patients. Gastroenterology 1987;93(1):48-52

5 Hicks ME, Surratt RS, Picus D, Marx MV, Lang EV. Fluoroscopically guided percutaneous gastrostomy and gastroenterostomy: analysis of 158 consecutive cases. AJR Am J Roentgenol 1990;154(4):725-728

6 Wollman B, D'Agostino HB, Walus-Wigle JR, Easter DW, Beale A. Radiologic, endoscopic, and surgical gastrostomy: an institutional evaluation and meta-analysis of the literature. Radiology 1995;197(3):699-704

7 Hoffer EK, Cosgrove JM, Levin DQ Herskowitz MM, Sclafani SJA. Radiologic gastrojejunostomy and percutaneous endoscopic gastrostomy: a prospective, randomized comparison. J Vasc Interv Radiol 1999;10(4):413-420

8 Richter-Schrag HJ, Richter S, Ruthmann O, Olschewski M, Hopt UT, Fischer A. Risk factors and complications following percutaneous endoscopic gastrostomy: a case series of 1041 patients. Can J Gastroenterol 2011;25(4):201-206

9 Lewis S, Jackson S, Latchford A. Randomized study of radiologic vs endoscopic placement of gastrojejunostomies in patients at risk of aspiration pneumonia. Nutr Clin Pract 2014;29(4):498-503

10 McDermott CJ; ProGas Study Group. Gastrostomy in patients with amyotrophic lateral sclerosis (ProGas): a prospective cohort study. Lancet Neurol 2015;14(7):702-709

11 Lim JH, Choi SH, Lee C, et al. Thirty-day mortality after percutaneous gastrostomy by endoscopic versus radiologic placement: a systematic review and meta-analysis. Intest Res 2016;14(4):333-342

12 Wollman B, D'Agostino HB. Percutaneous radiologic and endoscopic gastrostomy: a 3-year institutional analysis of procedure performance. AJR Am J Roentgenol 1997; 169(6):1551-1553

13 Silas AM, Pearce LF, Lestina LS, et al. Percutaneous radiologic gastrostomy versus percutaneous endoscopic gastrostomy: a comparison of indications, complications and outcomes in 370 patients. Eur J Radiol 2005;56(1):84-90

14 Eze N, Jefford JM, Wolf D, Williamson P, Neild P. PEG and RIG tube feeding in head and neck patients: a retrospective review of complications and outcome. J Eval Clin Pract 2007;13(5):817-819

15 Galaski A, Peng WW, Ellis M, Darling P, Common A, Tucker E. Gastrostomy tube placement by radiological versus endoscopic methods in an acute care setting: a retrospective review of frequency, indications, complications and outcomes. Can J Gastroenterol 2009;23(2):109-114

16 La Nauze RJ, Collins K, Lyon S, et al. Outcomes of percutaneous endoscopic gastrostomy versus radiologically inserted gastrostomy tube insertion at a tertiary hospital. ESPEN J 2012; 7(4):144-148

17 Allen JA, Chen R, Ajroud-Driss S, et al. Gastrostomy tube placement by endoscopy versus radiologic methods in patients with ALS: a retrospective study of complications and outcome. Amyotroph Lateral Scler Frontotemporal Degener 2013;14(4):308-314

18 Barkmeier JM, Trerotola SO, Wiebke EA, et al. Percutaneous radiologic, surgical endoscopic, and percutaneous endoscopic gastrostomy/gastrojejunostomy: comparative study and cost analysis. Cardiovasc Intervent Radiol 1998;21(4):324-328 